\title{
Orbital Lipoma as an Uncommon Cause of Unilateral Proptosis: A Case Report
}

This article was published in the following Dove Press journal:

International Medical Case Reports Journal

\author{
Pranav Shrestha ${ }^{\prime}{ }^{\prime}$ \\ Gulshan Bahadur Shrestha $\mathbb{1}^{2}$ \\ 'Mechi Eye Hospital, Jhapa, Nepal; \\ ${ }^{2}$ Department of Ophthalmology, Institute \\ of Medicine, Tribhuwan University \\ Teaching Hospital, Kathmandu, Nepal
}

\begin{abstract}
A 36 year old male presented with a two-month history of a progressively increasing proptosis of the right eye associated with redness. MRI of brain and orbit revealed a mass in the intraconal compartment in the lateral aspect of the right orbit that had T1, T2, and FLAIR high signal intensity and was completely suppressed in the STIR image. Excisional biopsy of the mass resolved the proptosis, and histology revealed encapsulated tumor composed of lobules of mature adipocytes along with fibro collagenous septa. Thus, diagnosis of lipoma was established that has uncommon occurrence in the orbital region.
\end{abstract}

Keywords: orbital, lipoma, proptosis, orbitotomy

\section{Introduction}

Lipoma is the most common mesenchymal neoplasm; conventionally in people aged over 40 years, occurring in the superficial soft tissue in the neck, shoulder and back. ${ }^{1}$ Despite the presence of abundant periorbital and retro bulbar fat, benign lipoma is uncommon in the orbital region with the reported incidence of $0.6 \%$ in a large orbital tumor series. ${ }^{2}$

These are well-circumscribed, asymptomatic with gradual growth, behaving as a mass that displace rather than infiltrate the surrounding tissue and may lead to exophthalmos.

They have distinct low attenuation on CT scan and do not enhance on contrast, while they are hyperintense on T1 weighted images and follow surrounding fatty signal on all images in MRI. They are composed of lobulated mature adipose tissue surrounded by a fine capsule histologically. ${ }^{2}$

Herein we present a case of orbital lipoma. The study adhered to the tenets of the Declaration of Helsinki. Although institutional approval was not required as it was case report, the patient has provided written consent to publish the case details and photographs.

\section{Case Report}

A male aged 36 years presented with forward budging of the right eye for 2 months, which was gradual in onset, progressive with no change in size during straining. It was associated with on and off redness of the right eye (Figure 1A). There was no history of trauma, diminution of vision, pain or double vision. He had initially consulted an eye hospital where he was advised for thyroid function test and CT scan of head and orbit.
Correspondence: Pranav Shrestha Mechi Eye Hospital, Sainik Mode, Birtamode 7, Jhapa 57204, Nepal Tel +977985I207295

Email stha.pranav@gmail.com
International Medical Case Reports Journal 2020:13 415-418 


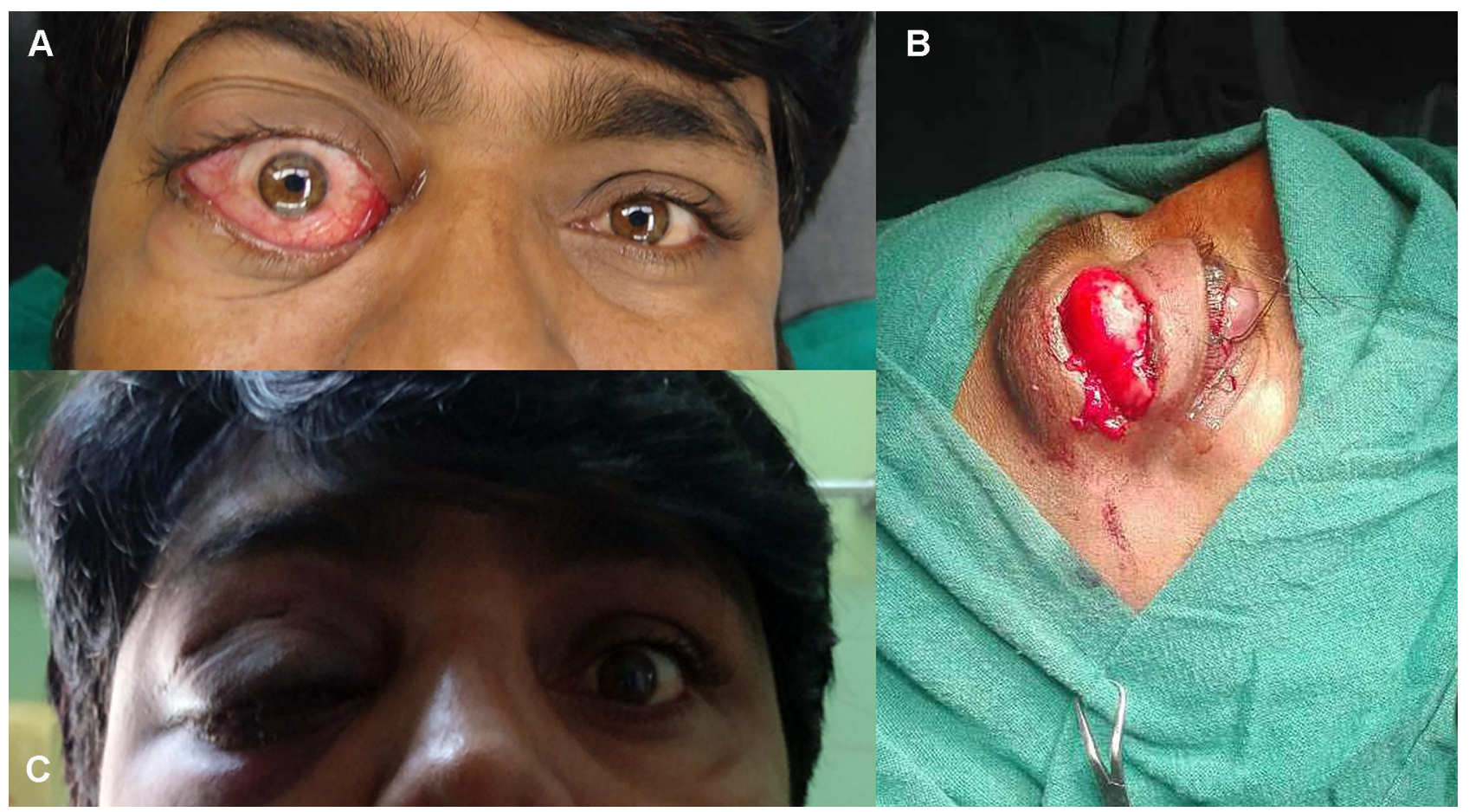

Figure I Clinical photograph. (A) Preoperative photograph showing proptosis of right eye. (B) Intraoperative photograph of right transcutaneous transeptal superior anterior orbitotomy and excisional biopsy. (C) One month postoperative photograph of right eye.

On ocular examination, he had visual acuity of 20/20 in both eyes. Lid retraction was present in the right eye, however lagophthalmos was not present. He had an axial proptosis of $12 \mathrm{~mm}$ in the right eye with positive resistance to retropulsion and fluctuating fatty mass could be palpated in the lateral aspect of the orbit. Nevertheless, extraocular motility was full in all the cardinal gazes in both the eyes.

His anterior segment and fundus evaluation were within normal limits with pupils being round, regular and reacting to both direct and consensual light without relative afferent pupillary defect. Thyroid function test was also normal.

CT scan of head and orbit revealed proptosis with slight inferior displacement of right eyeball. There was prominence of retro bulbar fat spaces between the optic nerve and lateral rectus muscle with indentation over the retrobulbar portion of optic nerve and right lateral muscle. No surrounding inflammatory or bony changes were noted.

MRI of brain and orbit was done, which revealed a $5.5 \dot{\times} 2 \dot{\times} 2.5 \mathrm{~cm}$ sized T1, T2, and Fluid Attenuation Inversion Recovery (FLAIR) high signal intensity mass in the intraconal compartment in the lateral aspect of the right orbit. This was completely suppressed in the Short T1 Inversion Recovery (STIR) images (Figure 2). The mass was displacing the optic nerve medially and globe anteriorly with resultant proptosis. No enhancement was seen in post contrast images. All these findings indicated a possible diagnosis of orbital lipoma and was differentiated from orbital fat prolapse due to presence of proptosis, resistance to retropulsion, nonfluctuating nature of the mass on external pressure and additional evidence from imaging.

He underwent right transcutaneous transeptal superior anterior orbitotomy and excisional biopsy under general anesthesia. After painting and draping, traction suture was placed in the gray line of the upper lid; the upper lid crease incision about $2.5 \mathrm{~cm}$ was given in the lateral two thirds of the upper lid; orbicularis was separated; orbital septum identified and opened; mass was identified and dissected off the surrounding tissue (Figure 1B); the entire mass was separated and removed in total; the orbit was inspected for any remaining mass, and the septum was closed after washing with antibiotic and wound was closed in layers.

The mass measured $5 \dot{\times} 5 \mathrm{~cm}$ and pale yellow in color with overlying capsule (Figure 3A). It was sent for histopathological examination. The dispatched histopathological report revealed encapsulated tumor composed of lobules of mature adipocytes along with fibro collagenous septa, with the final diagnosis of lipoma (Figure 3B).

Postoperatively, the patient last followed-up two months after surgery. He had visual acuity of 20/20 with full range of extraocular motility. Proptosis had completely subsided 


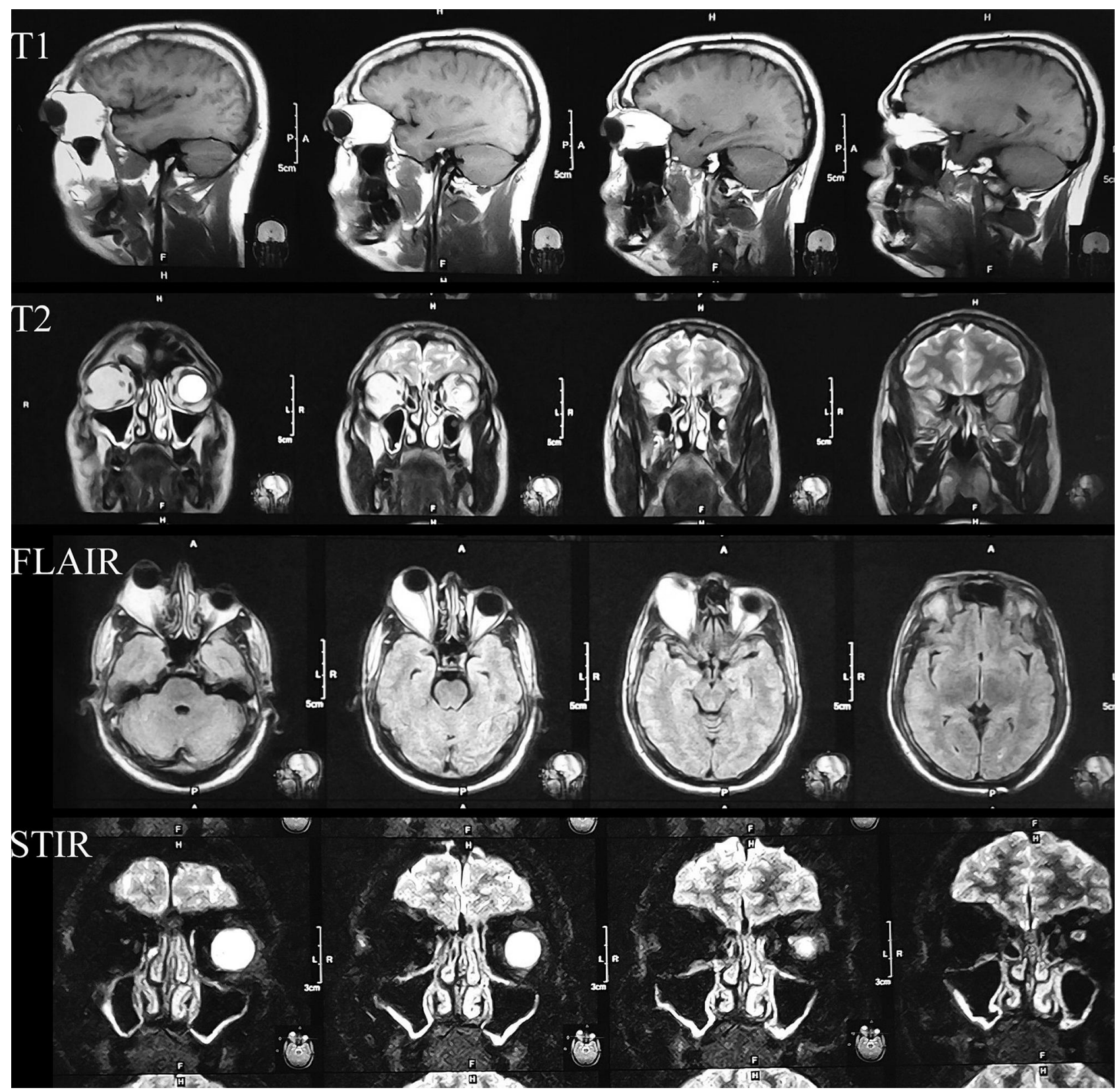

Figure 2 Clinical photograph. MRI TI, T2, FLAIR high signal intensity mass seen in intraconal compartment in lateral aspect of right orbit and MRI STIR images with lesion completely suppressed.

but the patient did have mild ptosis (Figure 1C). Nevertheless the patient was very satisfied with the outcome.

\section{Discussion}

A true lipoma is an encapsulated benign tumor composed of adult fat cells separated by fibrous septa. ${ }^{3}$ Although its occurrence is common in the subcutaneous tissue, it is rarely found in the orbit despite the presence of abundant fatty tissue. ${ }^{2,4}$

A study by Shield et $\mathrm{al}^{5}$ in 2004 reviewed 1264 patients with orbital lesions and noted only two patients with lipoma whose average age was 35 years. The reported incidence is largest in a pre-imaging era report by Forrest with its incidence being $8.5 \%$ (19 out of 222). ${ }^{2}$ On reviewing the literature this is the first reported case from Nepal with another case being mentioned in the study by Bastola et al. ${ }^{6}$

Orbital lipoma arises mainly from the anterior orbit. It is usually well-circumscribed and may be clinically obvious and palpable before the proptosis becomes visible. Generally, it is asymptomatic until it becomes large. ${ }^{2}$ 


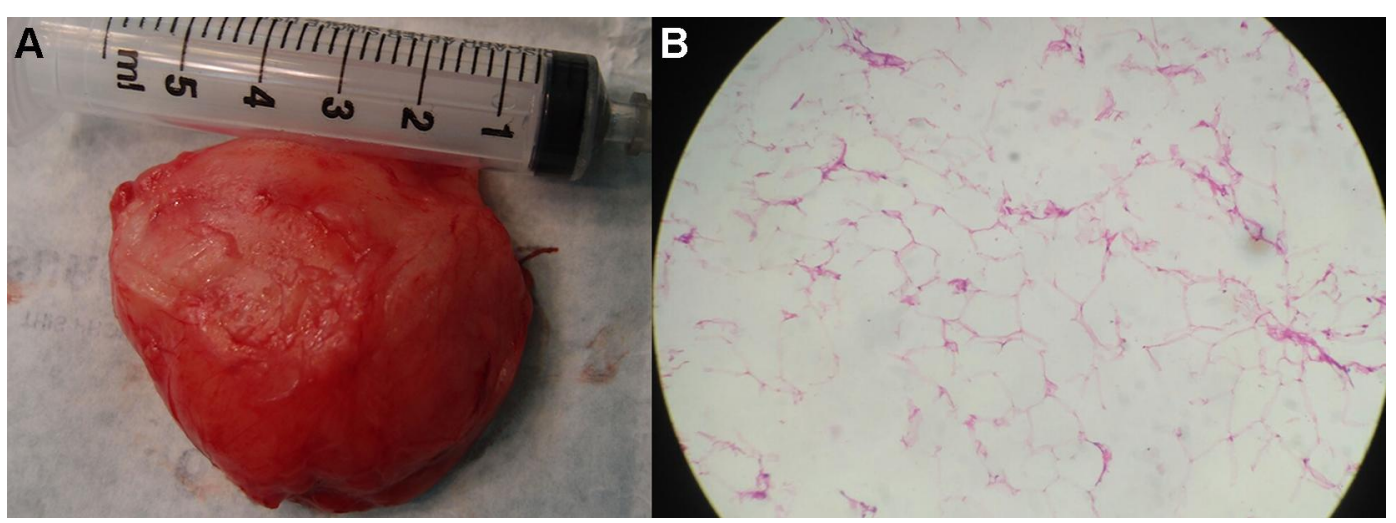

Figure 3 Clinical photograph. (A) Gross examination of specimen reveals a well encapsulated $4.3 \dot{\times} 4.5 \dot{\times} 2 \mathrm{~cm}$, yellowish gray mass. (B) H\&E stain shows tumor composed of lobules of mature adipocytes along with fibro collagenous septa ( $\dot{\times} 10$ magnification).

Orbital lipoma rarely grows and compresses the optic nerve resulting in disturbance in visual function including decreased visual acuity, relative afferent pupillary defect and visual field defect. ${ }^{7}$ In our case, the finding and history was similar to that of $\mathrm{Chi}^{\mathrm{et}} \mathrm{al}^{7}$ from Korea but unlike their case, our case did not have disturbance of visual function.

On CT scan, typically lipoma appears as distinctive low attenuation lesion sometimes with a finely defined border. On MRI, it is hyperintense on T1 weighted image. However, it is not enhanced after contrast. ${ }^{8}$ Histologically, lipoma is composed of lobulated mature adipose tissue surrounded by a fine capsule. ${ }^{2}$

Surgical excision is the recommended treatment for orbital lipoma. It is done not only for diagnosis and symptomatic relief, but also to rule out malignancy. ${ }^{9}$ The longterm outcome after surgery is seen to be excellent. ${ }^{2}$ Our case obliges with all of these reported findings.

In conclusion, a well circumscribed mass of orbital lipoma can result in proptosis of the eyeball, which is an uncommon cause; surgical excision of the mass can result in long-term excellent outcome cosmetically, helps to rule out malignancy and establish a histological diagnosis.

\section{Disclosure}

The authors report no conflicts of interest in this work.

\section{References}

1. Stock N. [Adipocytic tumors]. Ann Pathol. 2015;35(1):41-53. doi:10.1016/j.annpat.2014.12.001

2. Shah NB, Chang WY, White VA, Heran MKS, Rootman J. Heran MK and Rootman J. Orbital lipoma: 2 cases and review of literature. Ophthal Plast Reconstr Surg. 2007;23(3):202-205. doi:10.1097/ IOP.0b013e318050ca52

3. Jones IS, Reese A, Kraut J. Orbital Rhabdomyosarcoma*: an Analysis of 62 Cases. Am J Ophthalmol. 1966;61(4):721-736. doi:10.1016/ 0002-9394(66)91210-4

4. Ali SF, Farber M, Meyer DR. Farber M and Meyer DR. Fibrolipoma of the orbit. Ophthal Plast Reconstr Surg. 2013;29(3):e79-e81. doi:10.1097/IOP.0b013e318272f32b

5. Shields JA, Shields CL, Scartozzi R. Shields CL and Scartozzi R. Survey of 1264 patients with orbital tumors and simulating lesions: the 2002 Montgomery Lecture, part 1. Ophthalmology. 2004;111 (5):997-1008. doi:10.1016/j.ophtha.2003.01.002

6. Bastola P, Koirala S, Pokhrel G, Ghimire P, Adhikari R, ClinicoHistopathological A. Study of Orbital and Ocular Lesions; a Multicenter Study. J Chitwan Med Coll. 2013;3(2):40-44. doi: $10.3126 /$ jcmc.v3i2.8442

7. Chi MJ, Roh JH, Lee JH, Paik HJ. Lee JH and Paik HJ. A case of orbital lipoma with exophthalmos and visual disturbance. Jpn J Ophthalmol. 2009;53(4):442-444. doi:10.1007/s10384-009-0679-2

8. Brown HH. Kersten RC and Kulwin DR. Lipomatous hamartoma of the orbit. Arch Ophthalmol. 1991;109(2):240-243. doi:10.1001/ archopht.1991.01080020086050

9. Reibel JF, Greene WM. Liposarcoma arising in the pharynx nine years after fibrolipoma excision. Otolaryngol Head Neck Surg. 1995;112 (4):599-602. doi:10.1177/019459989511200417
International Medical Case Reports Journal

\section{Publish your work in this journal}

The International Medical Case Reports Journal is an international, peer-reviewed open-access journal publishing original case reports from all medical specialties. Previously unpublished medical posters are also accepted relating to any area of clinical or preclinical science. Submissions should not normally exceed 2,000 words or 4 published pages including figures, diagrams and references. The manuscript management system is completely online and includes a very quick and fair peer-review system, which is all easy to use. Visit http://www.dovepress.com/testimonials.php to read real quotes from published authors. 